\title{
Study of Band Gap of Silver Nanoparticles-Titanium Dioxide Nanocomposites
}

\author{
P. Barone, ${ }^{1,2}$ F. Stranges, ${ }^{1,2}$ M. Barberio, ${ }^{1,2}$ D. Renzelli, ${ }^{1}$ A. Bonanno, ${ }^{1}$ and F. Xu ${ }^{1}$ \\ ${ }^{1}$ Physics Department, University of Calabria, Via Bucci 31C, 87036 Rende, Italy \\ ${ }^{2}$ Biology, Ecology and Earth Science Department, University of Calabria, Via Bucci 4B, 87036 Rende, Italy \\ Correspondence should be addressed to P. Barone; pasquale.barone@fis.unical.it
}

Received 8 January 2014; Accepted 21 March 2014; Published 9 April 2014

Academic Editor: Mallikarjuna N. Nadagouda

Copyright (c) 2014 P. Barone et al. This is an open access article distributed under the Creative Commons Attribution License, which permits unrestricted use, distribution, and reproduction in any medium, provided the original work is properly cited.

\begin{abstract}
The optical and chemical properties of $\mathrm{Ag} / \mathrm{TiO}_{2}$ nanocomposites were investigated to explore the possibilities of incorporating these new materials in Gratzel photoelectrochemical cells. The nanocomposites were obtained doping $\mathrm{TiO}_{2}$, in both allotropic species anatase and rutile, with silver nanoparticles (grown by laser ablation process). X-ray photoelectron data indicate the absence of Ag-Ti chemical bonds, while measurements of photoluminescence and optical absorbance in UV-visible range show a quench in photoluminescence emission of about $50 \%$ and an increase in visible absorbance of about $20 \%$. Measurements of optical band gap, obtained by Tauc's equation, indicate a variation of about $1.6 \mathrm{eV}$.
\end{abstract}

\section{Introduction}

In recent decades, the scientific community has devoted much effort to the enhancement of the field of energy savings through the use of renewable energy.

Although solid state junction devices with high efficiency dominate the commercial market, these photovoltaic technologies still receive constraints in market development due to both of expensive materials and complex manufacturing process. Consequently, the emerging photovoltaic technologies, such as organic and inorganic cells, quantum dots, and dye sensitized solar cells, have attracted extensive attention because of their promising inexpensive technique based on the solution-processed materials. However, these new devices seem to be associated with unsatisfactory efficiency (with value which ranges between $7 \%$ and $20 \%$ on laboratory prototypes) due of chemical and physical characteristics of employed materials.

Recently, the interest has been focused on the application of nanostructured materials on dye sensitized solar cells (DSSCs). DSSCs mainly consist of a dye-sensitized $\mathrm{TiO}_{2}$ film deposited onto a transparent conducting substrate as the photoanode (working electrode), a redox active electrolyte, and a Pt cathode (counter electrode $\mathrm{CE}$ ). The use of $\mathrm{TiO}_{2}$ (in both of its mineral phases, rutile and anatase) in DSSCs is suggested by its high chemical stability, excellent functionality, nontoxicity, optical proprieties (absorption of UV solar radiation), and relatively low cost [1-3].

However, the low efficiency of DSSCs is linked to different factors as dye deterioration, electron/hole recombination in $\mathrm{TiO}_{2}$-dye substrate, and contact resistance between CE and electrolyte [1-3]. Moreover, the employ of titanium dioxide in solar cells is limited due of its transparency to visible light (only UV radiation is adsorbed and can be useful for photocatalytic activity) [4-8]. So, it is of great interest to extend the absorption wavelength of $\mathrm{TiO}_{2}$ to the visible region. This objective can be reached introducing various dopants into titanium dioxide lattice [9-12]. This generates additional electronic states in the dioxide energy band gap causing changes in optical bands and, so, in absorbance [12]. Several studies on $\mathrm{TiO}_{2}$ doping with heteroatoms (C, N, and S) have shown that it can reduce the $\mathrm{TiO}_{2}$ optical band up to $0.8 \mathrm{eV}$ [12]. Particularly, study on C-doping lead to growth of more reactive photocatalytic materials [5-7]. In a previous study, we used a simple mixing method to make CNTs/TiO microcomposites [13-18]. The luminescence emission of these composites is strongly modified compared to pure 
$\mathrm{TiO}_{2}$ with a sensible reduction in the visible region [1316]. Moreover, in our recent work [15] we obtained carbon nanotube- $\mathrm{TiO}_{2}$ composite at $1.5 \%$ in weight that presented a decrease in the optical band of about $0.7 \mathrm{eV}$, a quench in photoluminescence of $50 \%$, and an increase in the visible optical absorption of $60 \%$.

Here we present a study of an alternative doping process with silver nanoparticle. The aim of this work is to characterize the optical gap of $\mathrm{Ag} / \mathrm{TiO}_{2}$ nanocomposites by the combined analysis of photoluminescence (PL) emission and UV absorbance. The data are further compared with X-ray photoelectron spectroscopy (XPS) measurements and SEM and AFM images to obtain information about chemical structures and morphology of grown nanocomposites.

\section{Materials and Methods}

2.1. Materials. Anatase powders were prepared with a simple sol-gel method (with temperature less than $900^{\circ} \mathrm{C}$ and using as precursor $\left.\mathrm{Ti}(\mathrm{OBu})_{4}\right)$ as reported in our previous work [19]. They are constituted by grains with dimension of about 400-600 nm (SEM images in Figure 1(a)). Rutile powders, purchased from "Inframat Advanced Materials, LLC", appear as grains with dimensions of about 100-200 nm (SEM images in Figure 1(b)).

We grow silver nanoparticles by a laser ablation process obtaining spherical and spheroid particles with dimensions of hundreds of $\mathrm{nm}$. Laser ablation process was taken on a silver plate (purity of 99.99\%) vertically placed in a glass vessel filled with $25 \mathrm{~mL}$ of acetone. The plate was irradiated for 3 minutes by the output of the first harmonic $(1064 \mathrm{~nm})$ of a Quanta-Giant series $710 \mathrm{Nd}$ :YAG laser operating at $20 \mathrm{~Hz}$ (laser power is fixed at $600 \mathrm{~mJ} /$ pulse). During the irradiation with the laser beam, the solution, initially transparent, gradually turns brownish-yellow indicating the formation of $\mathrm{Ag}$ nanoparticles in solution [20,21]. After the LA, the solution was sonicated to prevent the self-aggregation of nanoparticles suspended in acetone and the formation of macrocluster.

The $\mathrm{Ag} / \mathrm{TiO}_{2}$ nanocomposites were prepared using a simple mixing method [13-17] with a sequence of mixing and heating processes. First, $100 \mathrm{mg}$ of $\mathrm{TiO}_{2}$ powder was dispersed in $10 \mathrm{~mL}$ of aqueous solution of acetic acid $\left(\mathrm{H}_{3} \mathrm{COOH}-93.7 \%\right)$ and then mixed to obtain a paste. The suspension was then added to acetone solution of silver nanoparticles and heated on a hot plate at about $150^{\circ} \mathrm{C}$ to facilitate the acetone evaporation. Finally, the compound of $\mathrm{Ag}$ and $\mathrm{TiO}_{2}$ was deposited on a clean copper plate $(2 \mathrm{~cm}$ $\times 2 \mathrm{~cm}$ in size) forming a thin film of about $500 \mu \mathrm{m}$ and heated in a muffle furnace at $450^{\circ} \mathrm{C}$ to complete evaporation of acetic acid and correct arrangement of $\mathrm{TiO}_{2}$ molecules. During mixing process, we do not observe any changes in allotropic form of anatase and rutile caused by mixing or heating (the $\mathrm{TiO}_{2}$ molecular structure was monitored by FTIR measurements, not showed, before and after mixing process). We obtain two series (anatase or rutile) of $\mathrm{TiO}_{2}$ samples with different $\mathrm{Ag}$ nanoparticles amount simply varying the amounts of silver/acetone solution mixed with titanium dioxide suspensions (each series was prepared with 6,12, 25, and $50 \mathrm{~mL}$ of $\mathrm{Ag}$ nanoparticles solutionsAg6, Ag12, Ag25, and Ag50 samples, resp.). The obtained composites, showed in AFM and SEM images in Figure 2 (Ag50 samples as example for all), appeared as a uniform bulk of $\mathrm{TiO}_{2}$ grains with random insertion of $\mathrm{Ag}$ nanoparticles with dimensions of about $500 \mathrm{~nm}$ (see EDX details of Ag50 sample of nanoparticles in Figure 2(c)).

Surface roughness analysis, conducted from AFM images, does not show significative modification between pure $\mathrm{TiO}_{2}$ and nanocomposites. This clearly indicates that the doping with $\mathrm{Ag}$ nanoparticles does not damage the $\mathrm{TiO}_{2}$ film morphology.

2.2. Methods. Nanocomposites were characterized by Xray photoelectron spectroscopy, photoluminescence spectroscopy, and measurements of optical absorbance in the UVvisible range.

XPS measurements were taken in a UHV chamber (base pressure in the range of low $10^{-9}$ torr) by a nonmonochromatic Mg-K $\alpha$ X-ray $(h \nu=1253.64 \mathrm{eV})$. The energies of XPS spectra were calibrated with the $\mathrm{C} 1 \mathrm{~s}$ peak of a pure carbon sample (binding energy of $284.6 \mathrm{eV}$ ).

Photoluminescence (PL) and optical absorbance measurements were taken with an Olympus microscope (HORIBA Jobin Yvon) mounting objectives of 10x, 50x, and 100x magnifications. The microscope is equipped with a laser source at $378 \mathrm{~nm}$ (12 mW of power) for PL, a white lamp for absorbance measurements $(200-1500 \mathrm{~nm})$, and a Triax 320 (HORIBA Jobin Yvon) spectrometer working in the 200-1500 $\mathrm{nm}$ range.

We measured directly the reflected spectrum $\left(I_{r}(\lambda)\right)$ and obtained, simply assuming the transmittance to be null for bulk samples, the reflectance $(r(\lambda))$ and the absorbance $(\varepsilon(\lambda))$ as a function of wavelength by the following relation:

$$
\begin{gathered}
r(\lambda)=\frac{I_{r}(\lambda)}{I_{s}(\lambda)}, \\
\varepsilon(\lambda)=1-r(\lambda),
\end{gathered}
$$

where $I_{s}(\lambda)$ is the intensity of the source spectrum.

The Tauc's equation was used to determine the band gap $E_{g}$ from optical absorbance $\varepsilon(\lambda)$ :

$$
\omega^{2} \varepsilon=\left(h \omega-E_{g}\right)^{2}
$$

where $\omega=2 \pi / \lambda$. The plot of $\varepsilon^{1 / 2} / \lambda$ versus $1 / \lambda$ should be a straight line in the absorption range and $E_{g}$ can be readily evaluated with a linear fit plot.

The SEM and EDX measurements were performed using a Cambridge Stereoscan SEM, with a $20 \mathrm{keV}$ electron beam and a current of few pA (having a spot size of $\sim 1.4 \mathrm{~mm}^{2}$ ), while the AFM images are taken by an Icon Bruker AFM working in tapping mode. The images have a resolution of $512 \times 512$ lines and are acquired at scanning rate of $1 \mathrm{~Hz}$. The obtained images were processed with the Nanoscope software (provided by Bruker) to evaluate surface roughness. 


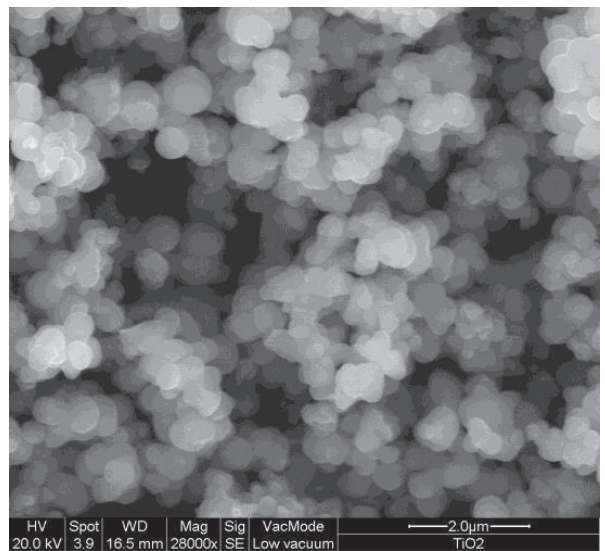

(a)

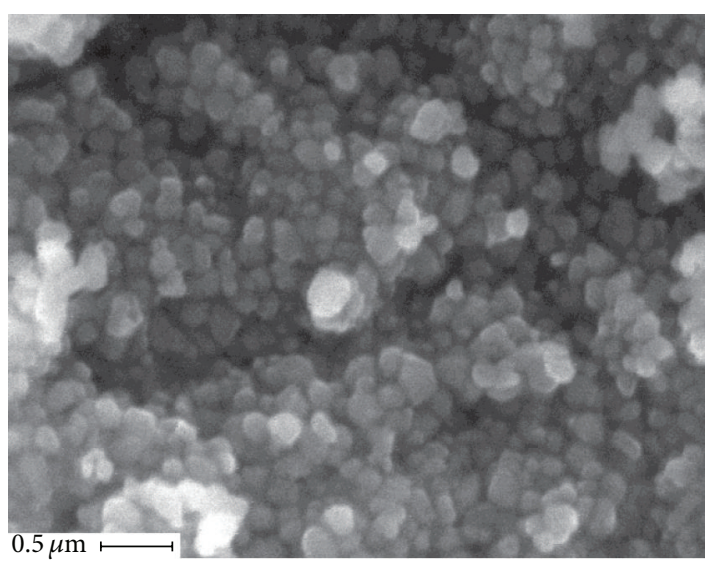

(b)

FIGURE 1: SEM images of anatase (a) and rutile (b) grains.

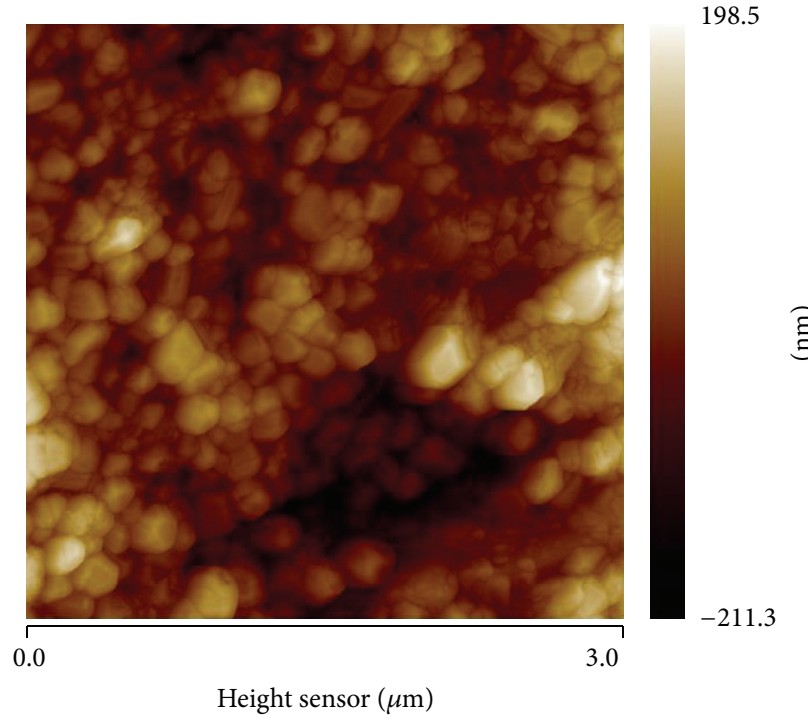

(a)

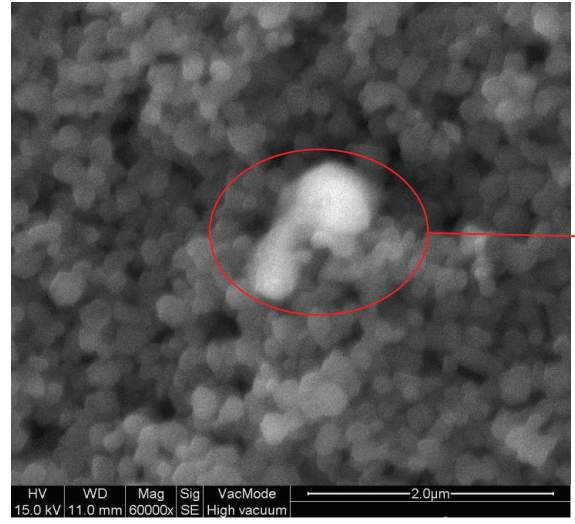

(b)

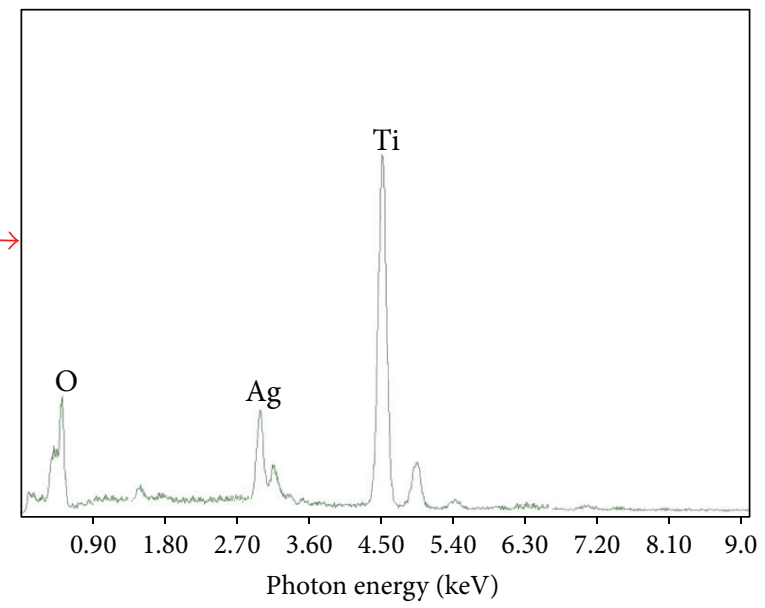

(c)

FigURE 2: AFM (a) and SEM (b) images of Ag/anatase composites obtained with the higher Ag percentage as example of all composites of both anatase and rutile series. EDX analysis (c) taken from anatase composites under SEM conditions. 


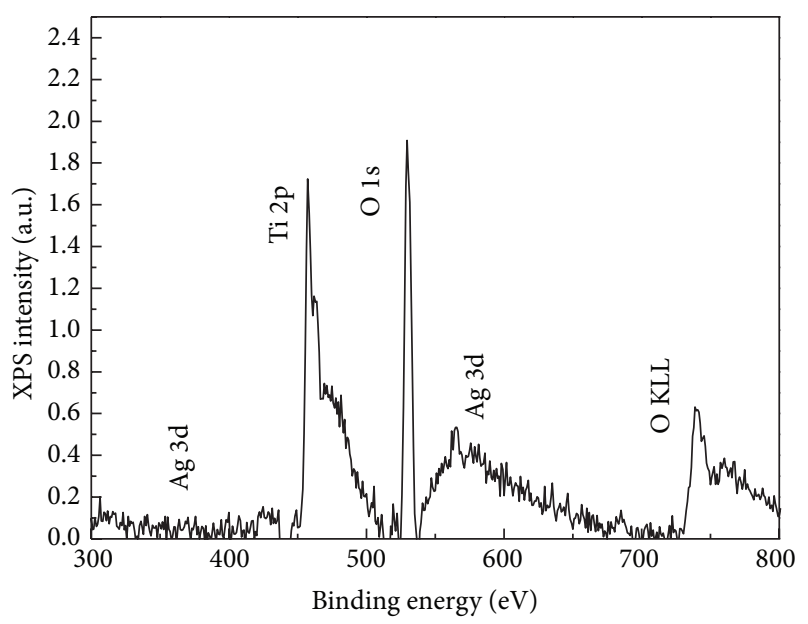

FigURE 3: XPS survey spectra for Ag50 anatase sample as example for all.

TABLE 1: Element's amount and XPS line position evaluated from XPS data.

\begin{tabular}{lcccccc}
\hline \multirow{2}{*}{ Sample } & \multicolumn{3}{c}{ Element's amount (\%) } & \multicolumn{3}{c}{ XPS line position (eV) } \\
& $\mathrm{Ti}$ & $\mathrm{O}$ & $\mathrm{Ag}$ & $\mathrm{Ti} 2 \mathrm{p} \mathrm{3/2}$ & $\mathrm{O} 1 \mathrm{~S}$ & $\mathrm{Ag} 3 \mathrm{~d} 5 / 2$ \\
\hline Anatase & 29.80 & 70.19 & & 459.16 & 530.29 & \\
Ag6/An & 30.73 & 68.90 & 0.30 & 459.57 & 529.24 & 368.30 \\
Ag12/An & 28.41 & 70.92 & 0.66 & 458.09 & 529.16 & 368.03 \\
Ag25/An & 28.15 & 70.75 & 1.09 & 457.82 & 529.75 & 369.30 \\
Ag50/An & 28.83 & 75.05 & 1.11 & 457.40 & 530.13 & 367.72 \\
Rutile & 22.70 & 77.30 & & 459.90 & 529.91 & \\
Ag6/Ru & 22.87 & 77.07 & 0.05 & 458.60 & 530.60 & 368.62 \\
Ag12/Ru & 24.18 & 75.74 & 0.07 & 458.20 & 530.40 & 368.11 \\
Ag25/Ru & 23.18 & 76.65 & 0.17 & 459.01 & 531.20 & 369.32 \\
Ag50/Ru & 21.58 & 78.22 & 0.2 & 459.10 & 529.20 & 369.20 \\
\hline
\end{tabular}

\section{Results and Discussion}

The chemical composition of our mixture and information on the bonding nature are obtained with XPS analysis and are summarized in Table 1. XPS spectra (in Figure 3, as example for all samples, the survey spectrum of An50) indicate in all composites only the presence of titanium, oxygen, and silver with surface concentration of each element as indicated in Table 1. In anatase series, the silver concentration on sample surface varies from $0.3 \%$ to $1 \%$ while in rutile heterostructures the silver concentration is lower varying from $0.05 \%$ to $0.2 \%$, denoting a different distribution of silver. This behavior can be explained both in terms of molecular structure and in terms of geometric dimension of nanoparticle grains (the silver amount in each corresponding sample is the same). In fact, the different molecular structure of rutile and anatase can affect the interaction between $\mathrm{TiO}_{2}$ molecules and $\mathrm{Ag}$ nanoparticle. Furthermore, the different size of rutile and anatase grains can modify the nanoparticles diffusion in the bulk (anatase grains, larger about 4 times than those of the rutile, can prevent the diffusion of the silver nanoparticles in the bulk of the composites). Moreover, for both anatase and rutile series the Ti-O ratio is not this of $1: 2$ expected from $\mathrm{TiO}_{2}$ stoichiometry indicating the presence in all samples of about $10 \%$ of oxygen impurities adsorbed in growth process (likely the adsorption occurred during the heating process in air at $450^{\circ} \mathrm{C}$ ).

Ti 2p 3/2 and O 1s XPS lines are centered in all samples at about 458 and $530 \mathrm{eV}$, characteristic of $\mathrm{TiO}_{2}$ molecules [21], while $\mathrm{Ag} 3 \mathrm{~d} 5 / 2$ lines are all centered at about $368 \mathrm{eV}$ denoting the presence on sample surfaces of both $\mathrm{Ag}-\mathrm{Ag}$ and $\mathrm{Ag}-\mathrm{O}$ chemical bonds [21]. Silver nanoparticles are highly sensitive to oxygen presence due to their elevated surface/volume ratio $[22,23]$. XPS data do not show any sign of chemical bonds between Ti-Ag, indicating the physisorption characteristic of doping process.

The photoluminescence emission of pure anatase and rutile samples, Figure 4, has two main structures centered at about 548 and $590 \mathrm{~nm}$ (inset of Figure 4) which are attributed to surface oxygen vacancies and associated to shallow energy levels below the conduction band [14]. The photoluminescence intensity decreases greatly with Ag nanoparticles doping and is quenched of about $50 \%$ for samples with higher percentage of $\mathrm{Ag}$ (in both anatase and rutile series). The absence of blue or red shift in PL bands confirms the absence of $\mathrm{Ti}-\mathrm{Ag}$ chemical bonds formation already observed from XPS data.

The optical absorbance (Figure 5) decreases in all UV region of about $20 \%$ for rutile and of about $5 \%$ for anatasebased nanocomposite. Fortunately, this decrease in UV absorbance is compensated from an increase in visible absorbance of about $20 \%$ for all composites. Moreover the optical band gap, calculated with Tauc's equation, shows a decrease from about $3 \mathrm{eV}$, typical of $\mathrm{TiO}_{2}(2.9$ for anatase and 3.1 for rutile), to about $1.4 \mathrm{eV}$ of nanocomposites at higher concentration of silver. These drastic decreases in optical band can explain both the quenching of photoluminescence and the changes in UV-visible absorption and clearly indicate a progressive metallization of samples caused by the $\mathrm{Ag}$ doping.

In our previous works [15], we demonstrate the effectiveness of CNT doping of titanium dioxide respect to Catom doping reaching a decrease of $0.7 \mathrm{eV}$ (decrease of about $25 \%$ ) in optical band gap with a doping of $1.5 \%$ of CNT. Here we obtain a further improvement with a silver nanoparticle doping with a decrease of about $50 \%$ in optical bands.

\section{Conclusions}

We have presented the results of effect of Ag nanoparticles doping on $\mathrm{TiO}_{2}$, for both anatase and rutile species. In both cases we observe that the doping process leads to a variation of $1.6 \mathrm{eV}$ in optical gap already at very low silver percentage (Ag6 samples), quenches the photoluminescence emission of about $50 \%$, and increases the optical absorbance in visible range of about the $20 \%$. All these results denote a progressive metallization of titanium dioxide and indicate the $\mathrm{Ag} / \mathrm{TiO}_{2}$ nanocomposites as good candidates to substitute pure $\mathrm{TiO}_{2}$ in Gratzel cells. In fact, the decrease of $1.6 \mathrm{eV}$ 


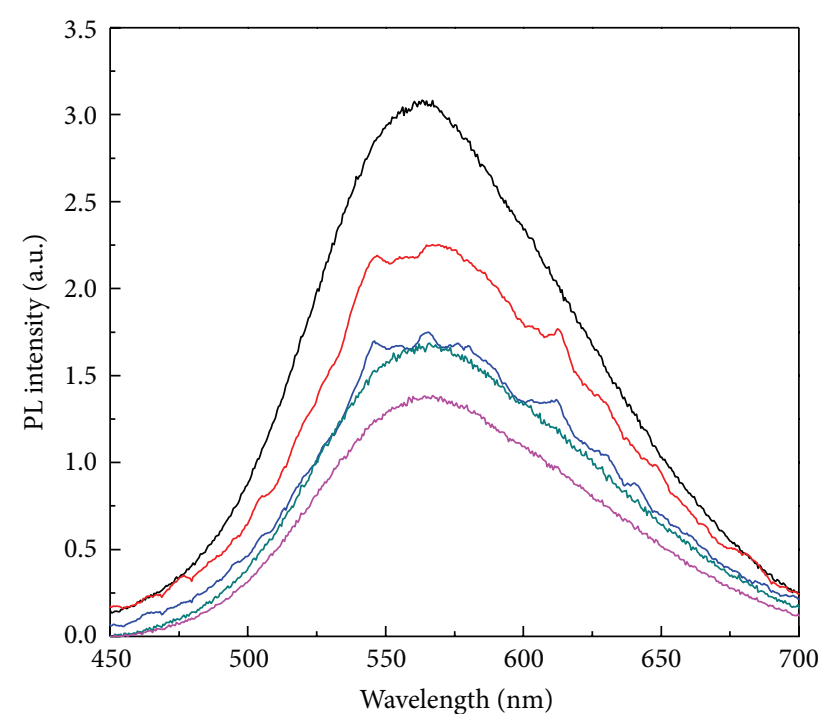

(a)

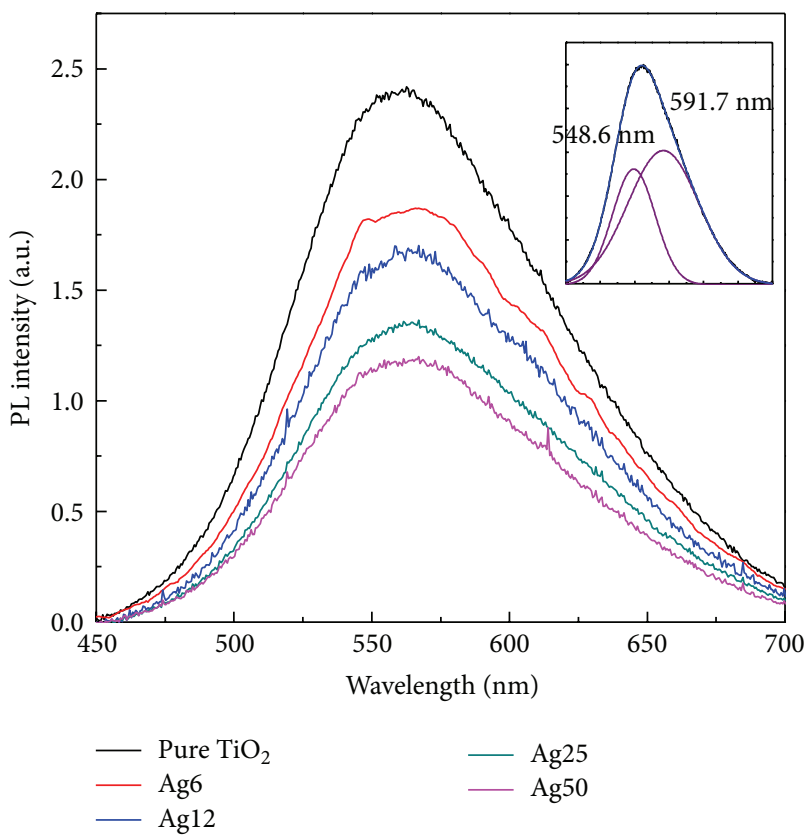

(b)

FIGURE 4: Photoluminescence spectra of nanocomposites (obtained at the higher Ag percentage) compared with those of pure $\mathrm{TiO} 2$ for both rutile (a) and anatase (b) series.

in optical band gap suggests a significative reduction of electron-hole recombination in dioxide (improving, so, the DSSCs efficiency). Many efforts are necessary to study the electrical properties of obtained nanocomposites before their introduction in photoelectrochemical cells.

\section{Conflict of Interests}

The authors declare that there is no conflict of interests regarding the publication of this paper.

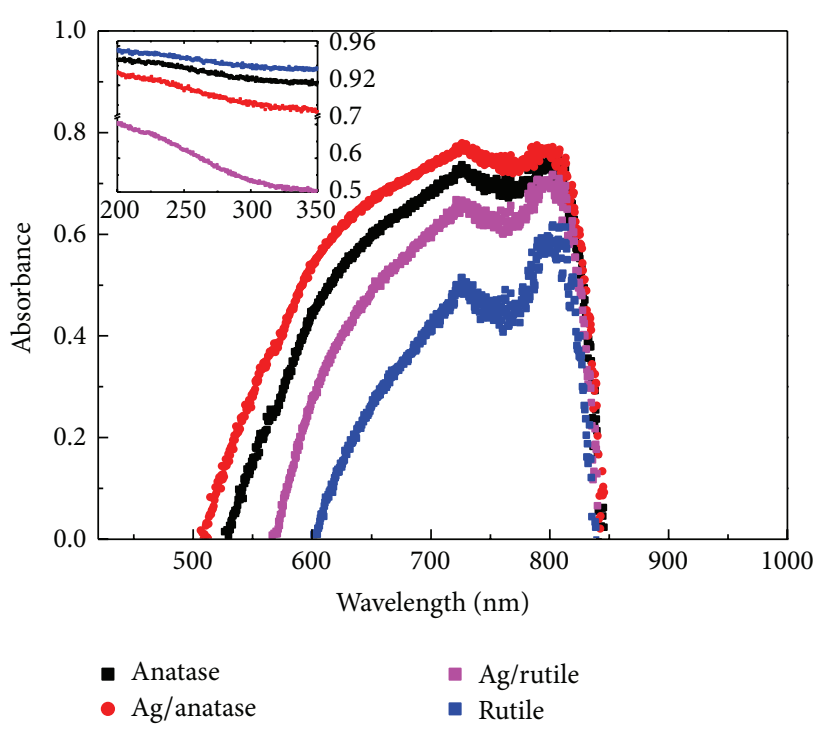

FIGURE 5: Visible absorbance spectra of nanocomposites (obtained at the higher Ag percentage) compared with those of pure $\mathrm{TiO}_{2}$ for both anatase and rutile series. Inset: UV absorbance.

\section{Acknowledgments}

This work has been funded from the European Project PON 042a_E "Res Novae". The authors thank Dr. Mariano Davoli from DiBEST Department, University of Calabria, for SEM images.

\section{References}

[1] M. Hemissi and H. Amardjia-Adnani, "Optical and structural properties of titanium oxide thin fils prepared by Sol-Gel method," Digest Journal of Nanomaterials and Biostructures, vol. 2, no. 4, pp. 299-305, 2007.

[2] J. Sabataityté, I. Oja, F. Lenzman, O. Volobujeva, and A. Krunks, "Characterization of nanoporous $\mathrm{TiO}_{2}$ films prepared by SolGel method," Comptes Rendus Chimie, vol. 9, no. 5-6, p. 708, 2006.

[3] R. Zallen and M. P. Moret, "The optical absorption edge of brookite $\mathrm{TiO}_{2}$," Solid State Communications, vol. 137, no. 3, pp. 154-157, 2006.

[4] A. R. Ghande and J. O. Fernandez, "A simple method to synthesize light active N-Doped anatase $\left(\mathrm{TiO}_{2}\right)$ photocatalyst," Bulletin of the Catalysis Society of India, vol. 4, pp. 131-134, 2005.

[5] K. Woan, G. Pyrgiotakis, and W. Sigmund, "Photocatalytic carbon-nanotube- $\mathrm{TiO}_{2}$ composites," Advanced Materials, vol. 21, no. 21, pp. 2233-2239, 2009.

[6] Y. Yao, G. Li, S. Ciston, R. M. Lueptow, and K. A. Gray, "Photoreactive $\mathrm{TiO}_{2} /$ carbon nanotube composites: synthesis and reactivity," Environmental Science and Technology, vol. 42, no. 13, pp. 4952-4957, 2008.

[7] R. I. Bickley, T. Gonzalez-Carreno, J. S. Lees, L. Palmisano, and R. J. D. Tilley, "A structural investigation of titanium dioxide photocatalysts," Journal of Solid State Chemistry, vol. 92, no. 1, pp. 178-190, 1991.

[8] M. Kaneko and I. Ohkura, Photocatalysis, Springer, Tokyo, Japan, 2002. 
[9] G. Zhang, X. Ding, Y. Hu et al., "Photocatalytic degradation of 4BS dye by N,S-codoped $\mathrm{TiO}_{2}$ pillared montmorillonitne photocatalysts under visible-light irradiation," Journal of Physical Chemistry C, vol. 112, no. 46, pp. 17994-17997, 2008.

[10] F. Wei, L. Ni, and P. Cui, "Preparation and characterization of NS-codoped $\mathrm{TiO}_{2}$ photocatalyst and its photocatalytic activity," Journal of Hazardous Materials, vol. 156, no. 1-3, pp. 135-140, 2008.

[11] Y. Gai, J. Li, S. S. Li, J. B. Xia, and S. H. Wei, "Design of narrow-gap $\mathrm{TiO}_{2}$ : a passivated codoping approach for enhanced photoelectrochemical activity," Physical Review Letters, vol. 102, Article ID 036402, 2009.

[12] X. Chen and C. Burda, "The electronic origin of the visible-light absorption properties of C-, $\mathrm{N}$ - and $\mathrm{S}$-doped $\mathrm{TiO}_{2}$ nanomaterials," Journal of the American Chemical Society, vol. 130, no. 15, pp. 5018-5019, 2008.

[13] M. Barberio, P. Barone, A. Bonanno, and A. Oliva, "Synthesis and characterization of carbon nanotubes wrapped on anatase microparticles," Particle and Particle Systems Characterization, vol. 28, no. 3-4, pp. 64-70, 2012.

[14] M. Barberio, P. Barone, V. Pingitore, and A. Bonanno, "Optical properties of $\mathrm{TiO}_{2}$ anatase-carbon nanotubes composites studied by cathodoluminescence spectroscopy," Superlattices and Microstructures, vol. 51, no. 1, pp. 177-183, 2012.

[15] M. Barberio, P. Barone, A. Imbrogno, F. Xu, V. Pingitore, and A. Bonanno, "Optical and structural properties of carbon nanotube-rutile heterostructures," Journal of Chemistry and Chemical Engineering, vol. 6, pp. 199-208, 2012.

[16] V. Pingitore, M. Barberio, P. Barone, and A. Oliva, "Photoluminescence properties of $\mathrm{LiF} / \mathrm{CNT}, \mathrm{ZnS} / \mathrm{CNT}, \mathrm{TiO}_{2} / \mathrm{CNT}$ composites," Nanoscience and Nanotechnology Letters, vol. 4, no. 11, pp. 1082-1086, 2012.

[17] A. Bonanno, M. Barberio, P. Barone et al., "Changes in electronic properties of carbon structures by evaporation and implantation of alkali metals," Vacuum, vol. 84, no. 8, pp. 10251028, 2010.

[18] M. Barberio, P. Barone, A. Imbrogno, A. Bonanno, and F. Xu, Open Journal of Composites Materials. In press.

[19] S. Ruffolo, A. Macchia, M. F. La Russa et al., "Marine antifouling for underwater archaeological sites: $\mathrm{TiO}_{2}$ and $\mathrm{Ag}$-Doped $\mathrm{TiO}_{2}$," International Journal of Photoenergy, vol. 2013, Article ID 251647, 6 pages, 2013.

[20] K. L. Kelly, E. Coronado, L. L. Zhao, and G. C. Schatz, "The optical properties of metal nanoparticles: the influence of size, shape, and dielectric environment," The Journal of the Physical Chemistry B, vol. 107, no. 3, pp. 668-677, 2003.

[21] "NIST XPS data base," http://www.srdata.nist.gov/xps/main _search_menu.aspx\%E2\%80\%8E.

[22] M. Barberio, P. Barone, V. Pingitore, and F. Xu, "Photoluminescence from silver/carbon nanotubes composites," Superlattice and Microstructures, vol. 57, pp. 129-138, 2013.

[23] M. Barberio, P. Barone, F. Stranges, A. Romano, F. Xu, and A. Bonanno, "Carbon nanotubes/metal nanoparticle based nanocomposites: improvements in Visible photoluminescence emission and hydrophobicity," Optics and Photonics Journal, vol. 3, pp. 34-40, 2013. 

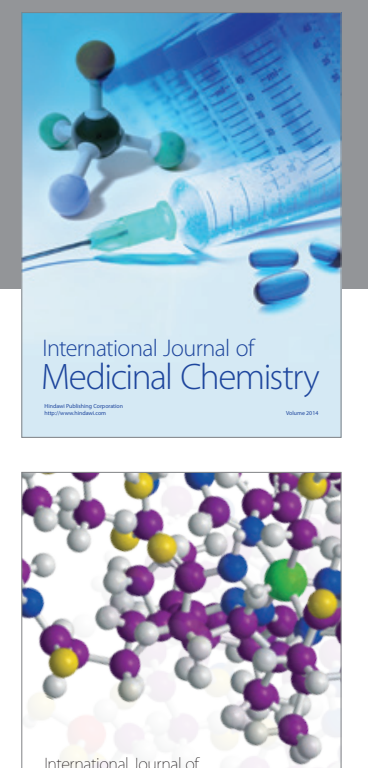

\section{Carbohydrate} Chemistry

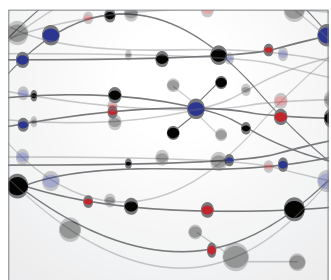

The Scientific World Journal
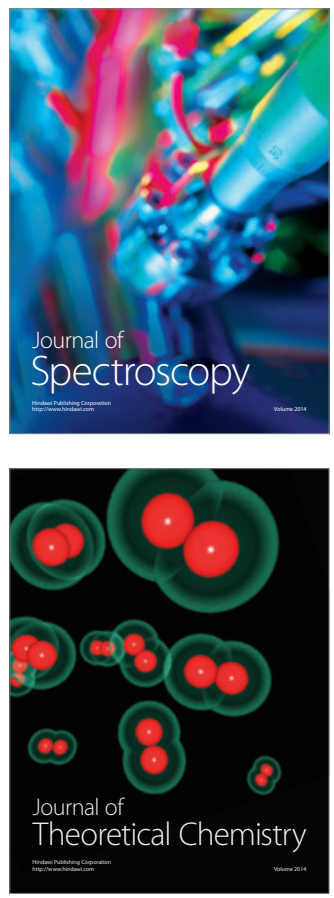
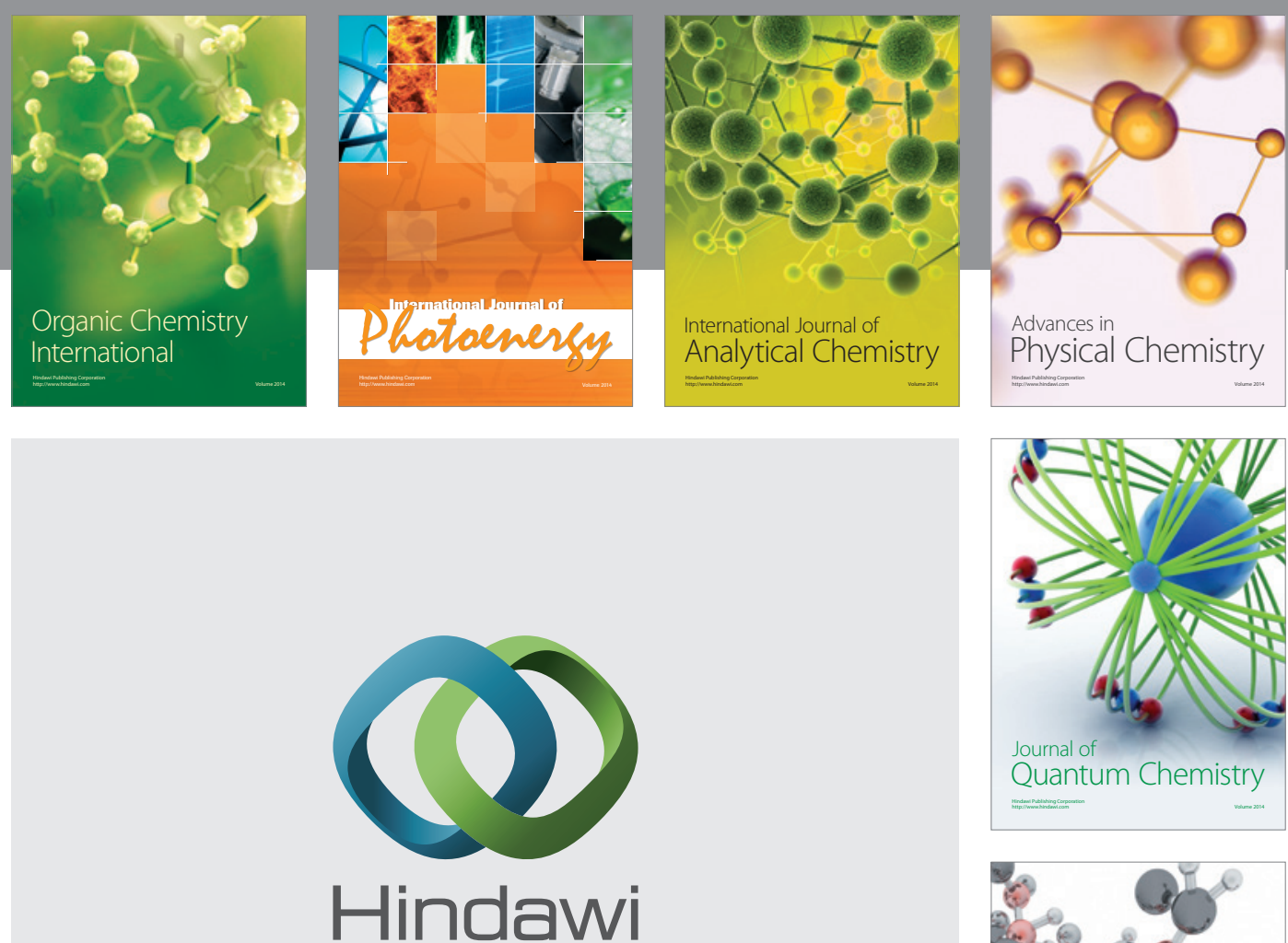

Submit your manuscripts at

http://www.hindawi.com

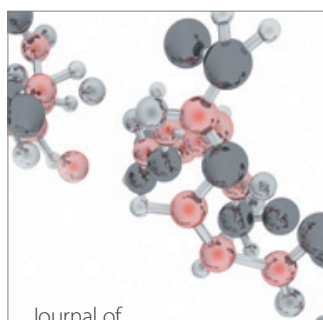

Analytical Methods

in Chemistry

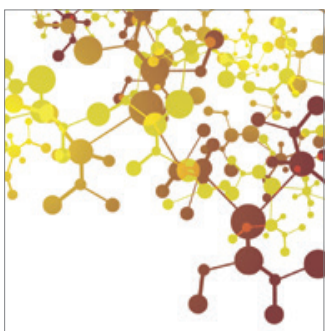

Journal of

Applied Chemistry

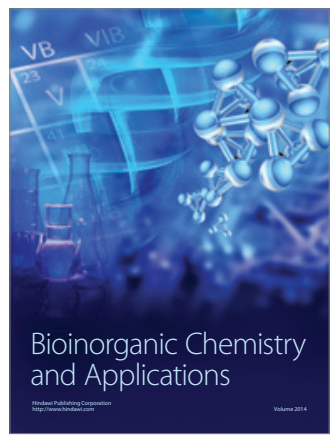

Inorganic Chemistry
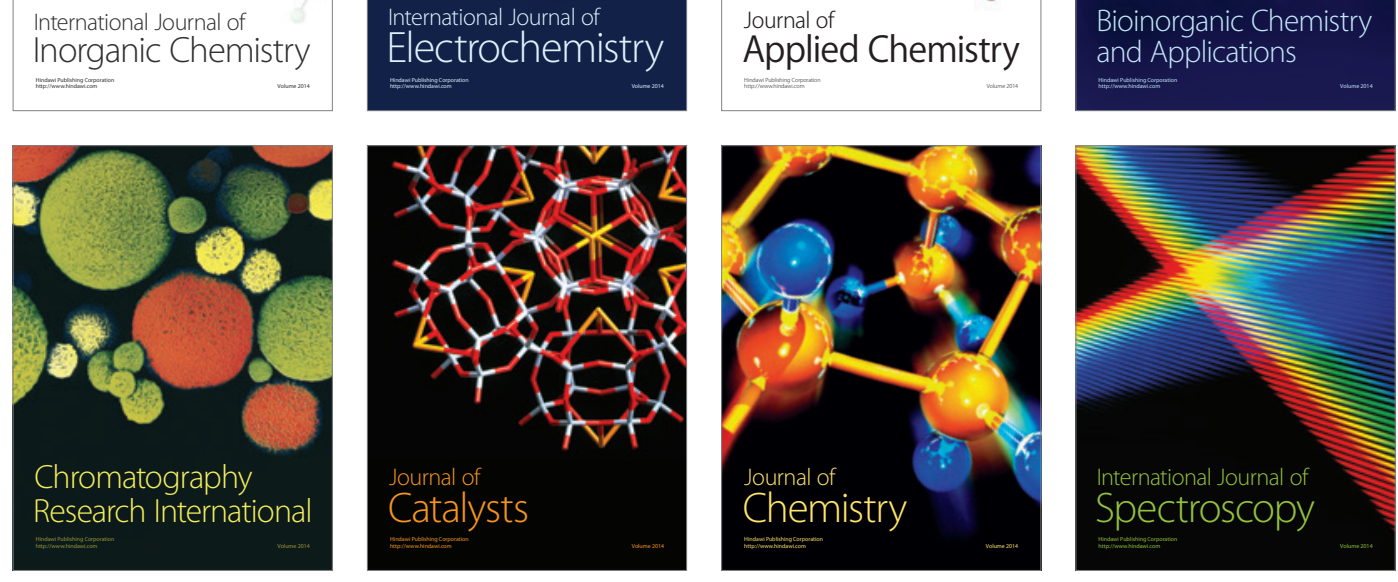